\title{
Quality of Life of Patients on Peritoneal Dialysis in Dakar: A Senegalese Single Centre Experience
}

\author{
Kane Yaya ${ }^{*}$, Cisse Mouhamadou Moustapha², Seck Sidy Mohamed ${ }^{3}$, \\ Lemrabott Ahmed Tall' ${ }^{2}$, Faye Maria ${ }^{2}$, Hounsounou Christian', Diallo Kalilou', \\ Ka El Hadji Fary', Niang Abdou2 ${ }^{2}$, Diouf Boucar ${ }^{2}$

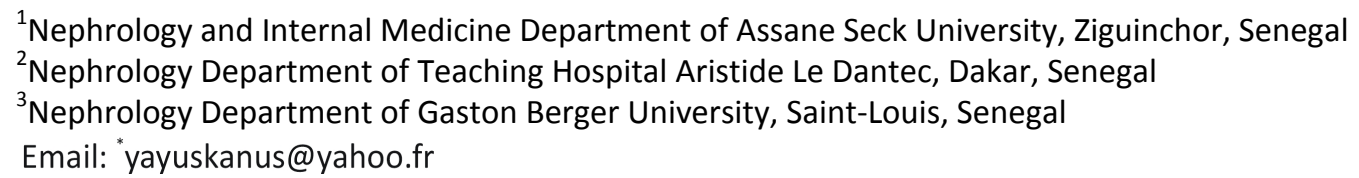

Received 13 April 2016; accepted 3 June 2016; published 6 June 2016

Copyright (C) 2016 by authors and Scientific Research Publishing Inc.

This work is licensed under the Creative Commons Attribution International License (CC BY).

http://creativecommons.org/licenses/by/4.0/

(c) (i) Open Access

\begin{abstract}
Introduction: Measuring the quality of life (QOL) in recent years has become an indispensable tool in monitoring patients suffering from chronic diseases. We conducted this study to assess QOL of patients undergoing peritoneal dialysis in Dakar, and to identify associated factors. Patients and Methods: This is a cross-sectional study which was carried out from 10 to 30 June, 2011 in the peritoneal dialysis unit at university hospital in Dakar. We included all patients with end-stage renal disease (ESRD) of any age, who were on PD since at least six months and who gave their consent. The QOL was assessed using the Kidney Disease Quality of Life Short-Form 1.2 (KDQoL-SF). Results: Sixteen patients were included with a mean age of $50.25 \pm 13.48$ years and a sex-ratio of 1.27. Considering SF-36, the overall mean score (SMG) was $60.11 \pm 15.96$ with a Mean Physical Component Summary Scale of $53.66 \pm 16.98$ and a Mental Component Summary Scale of 70.85 \pm 6.14. Concerning the KDQoL-SF, the global mean score was $61.83 \pm 19.35$ with a mean physical score of $50.55 \pm 16.52$ and a mean mental score of $62.52 \pm 21.53$. The mean dialysis specific dimension score was $62.52 \pm 21.53$ and the mean mental health score was $85.93 \pm 12.06$. Age, weight, level of instruction and social support were correlated with a worse QOL. Conclusion: This study showed an alteration of our PD patients' QOL, particularly in their physical health. However, the number of patients included in the study is not enough to permit a formal conclusion.
\end{abstract}

\section{Keywords}

Quality of Life, Peritoneal Dialysis, Dakar

\footnotetext{
${ }^{*}$ Corresponding author.
}

How to cite this paper: Yaya, K., Moustapha, C.M., Mohamed, S.S., Tall, L.A., Maria, F., Christian, H., Kalilou, D., Fary, K. El H., Abdou, N. and Boucar, D. (2016) Quality of Life of Patients on Peritoneal Dialysis in Dakar: A Senegalese Single Centre Experience. Open Journal of Nephrology, 6, 37-42. http://dx.doi.org/10.4236/ojneph.2016.62005 


\section{Introduction}

The quality of life (QOL) is undeniably a broad concept, especially when it is related to health and chronic disease but it has not yet been the subject of a public health plan. This measure is supposed to quantify the impact of diseases or medical interventions on the lives of patients in the subjective point of view [1] [2]. In Senegal, prevalence of chronic kidney disease is estimated to $4.9 \%$ and among these $0.2 \%$ require treatment by dialysis [3]. Peritoneal dialysis (PD) program started in Senegal since 2004 and contributed to treating more and more patients [4]. This study was conducted to evaluate the QOL of PD patients in Dakar and to identify the associated factors.

\section{Patients and Methods}

We conducted a descriptive cross-sectional study from June $10^{\text {th }}$ to $30^{\text {th }}$, 2011 in the peritoneal dialysis unit of University Hospital Aristide Le Dantec in Dakar. We included all patients with end-stage renal disease (ESRD) of any age, who were on PD since at least six months and who gave their consent. Patients with recent complications less than one month before and irregularly followed patients were excluded from the survey. QOL of the study population was assessed with the SF-36 [5] and the KDQoL-SF 1.2 [6] questionnaires. The short form 36, the generic module, includes 35 items corresponding to 8 fields divided into two dimensions:

- The physical dimension on "general health", "physical activity", "limitations due to physical activity", "physical pain", and "vitality".

- The mental health dimension on "limitations due to mental activity", "life and relations with others", and "mental health".

The KDQoL specific questionnaire tailored to kidney disease included 143 items divided into the following 19 areas:

- General health: D1

- Physical Activity: D2

- Limitations due to the physical condition: D3

- Physical pain: D4

- Vitality: D5

- Friendly and family relationships: D6

- Professional status: D7

- Limitations due to the mental state: D8

- Life and relationships with others: D9

- Mental health: D10

- Quality of the environment: D11

- The burden of kidney disease: D12

- Cognitive functions: D13

- Symptoms and problems: D14

- Effects of the disease on daily life: D15

- The quality of sexual activity: D16

- Sleep: D17

- Patient satisfaction: D18

- Encouragement by the dialysis team: D19

These areas are divided into four dimensions:

- Physical dimension on the "physical function", "professional status", "limitations related to physical state", "pain", "general health" and "energy".

- Mental health dimension on the "welfare”, "quality of social life”, "burden of disease”, "social support”, and "limitations related to psychological health".

- Dialysis specific dimension related to "cognitive function", "absence/presence of symptoms", "disability of dialysis on daily life", "sexual function" and "sleep".

- A dimension related to patient satisfaction on how it should be dealt with a question about "general satisfaction" and another about "support of the health care team".

Scoring responses on a scale of 0 to 100 where 0 is the worst quality of life and 100 the best. A score is calculated for each domain (SMD). This is the maximum $N$ score ratio an individual may have in the area and the 
patient's $n$ score in the field. It is expressed as a percentage and can identify the most affected areas. In addition, overall average score (SMG) corresponding to the mean SMD can assess each dimension. A better quality of life with a SMG high score has been noted. We opted firstly, seeking better interpretation of our results, for a standardized 50 with a standard deviation of 10 .

The living standard was evaluated using patients' monthly expenses. In all patients, the Charlson score was calculated [4] [7], as well as the number of peritonitis. Statistical analyzes were performed using SPSS 11.5 for Windows. Continuous variables were presented as mean \pm standard deviation and categorical variables as percentage. Comparison of proportions and means were done using Pearson's Chi-square test or Student's t-test as appropriated. Multivariate regression analysis was used to identify clinical and biological parameters associated with bad QOL. All statistical tests were considered significant if $\mathrm{p}<0.05$.

\section{Results}

In a total of 20 patients meeting the inclusion criteria but four patients were excluded for refusal. Thus, 16 patients participated in this study (acceptance rate of $80 \%$ ). The characteristics of the study population are shown in Table 1.

On the SF-36, the SMG was $60.11 \pm 15.96$. The score of physical health dimension is $53.66 \pm 16.98$ and that of the mental health dimension, $70.85 \pm 6.14$. SF-36 average scores (SMD) are shown in Figure 1.

For KDQoL, the SMG was $61.83 \pm 19.35$. The mean scores for each dimension were:

- Physical dimension: $50.55 \pm 16.5222$

- Mental health dimension: $66.52 \pm 14.1423$

- Dialysis specific dimension: $62.52 \pm 21.5324$

- The dimension on patient satisfaction: $85.93 \pm 12.0625$

The different SMD for KDQoL are shown in Figure 2.

Alteration of the quality of life was statistically significantly correlated with age in the D18 field $(p=0.01)$, with the weight in the D1 domains $(p=0.01)$, D2 $(p=0.03)$, D3 $(p=0.02)$ and D18 $(p=0.02)$, the level of education in the D3 $(\mathrm{p}=0.04)$ and social support in the D2 areas $(\mathrm{p}=0.01)$, D6 $(\mathrm{p}=0.04)$, D7 $(\mathrm{p}=0.01)$ and $\mathrm{D} 15(\mathrm{p}=0.01)$.

Table 1. Demographical and clinical characteristics of patients.

\begin{tabular}{|c|c|c|}
\hline Variables & N (Percent) & Mean (SD) \\
\hline Age (years) & & $50.25 \pm 13.48$ \\
\hline Sex-ratio (M/F) & 1.27 & \\
\hline \multicolumn{3}{|l|}{ Level of formal education } \\
\hline Primary & $03(18.75 \%)$ & \\
\hline Secondary & 05 (31.25\%) & \\
\hline University & $03(18.75 \%)$ & \\
\hline Illiterate & 05 (31.25\%) & \\
\hline Married & $13(81.25 \%)$ & \\
\hline Profession & $03(18.75 \%)$ & \\
\hline Without profession & $11(68.75 \%)$ & \\
\hline Retired & 02 (12.5\%) & \\
\hline Autonomous & 15 (93.75\%) & \\
\hline Social support & $12(75 \%)$ & \\
\hline Awareness of the disease & $15(100 \%)$ & \\
\hline Charlson score & & $03 \pm$ \\
\hline Weight (kg) & & $64.34 \pm$ \\
\hline APD & $01(06.2 \%)$ & \\
\hline CAPD & 15 (93.8\%) & \\
\hline Peritonitis & 03 episodes & \\
\hline
\end{tabular}


Living and relationships with the others

Physical pains

Physical activity

Psychic health

Limitations due to psychic activity

General health

Vitality

Limitations due to physical activity

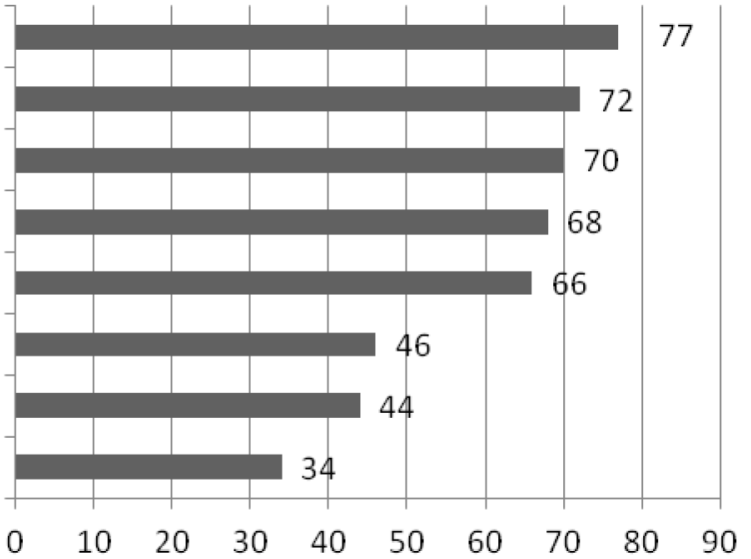

Figure 1. Summary Basis of Decisions (SBD) using SF-36.

Encouragements by the dialysis team

Quality of the environment

Cognitive functions

Living and relationships with the others

Patients' satisfaction

Physical pains

Physical activity

Symptoms and problems

Psychic health

Limitations due to psychic activity

Friendly and family relationships

Sleep

Impacts of the kidney disease

General health

Vitality

Quality of sexual activity

Limitations due to physical activity

Professional status

Disease burden

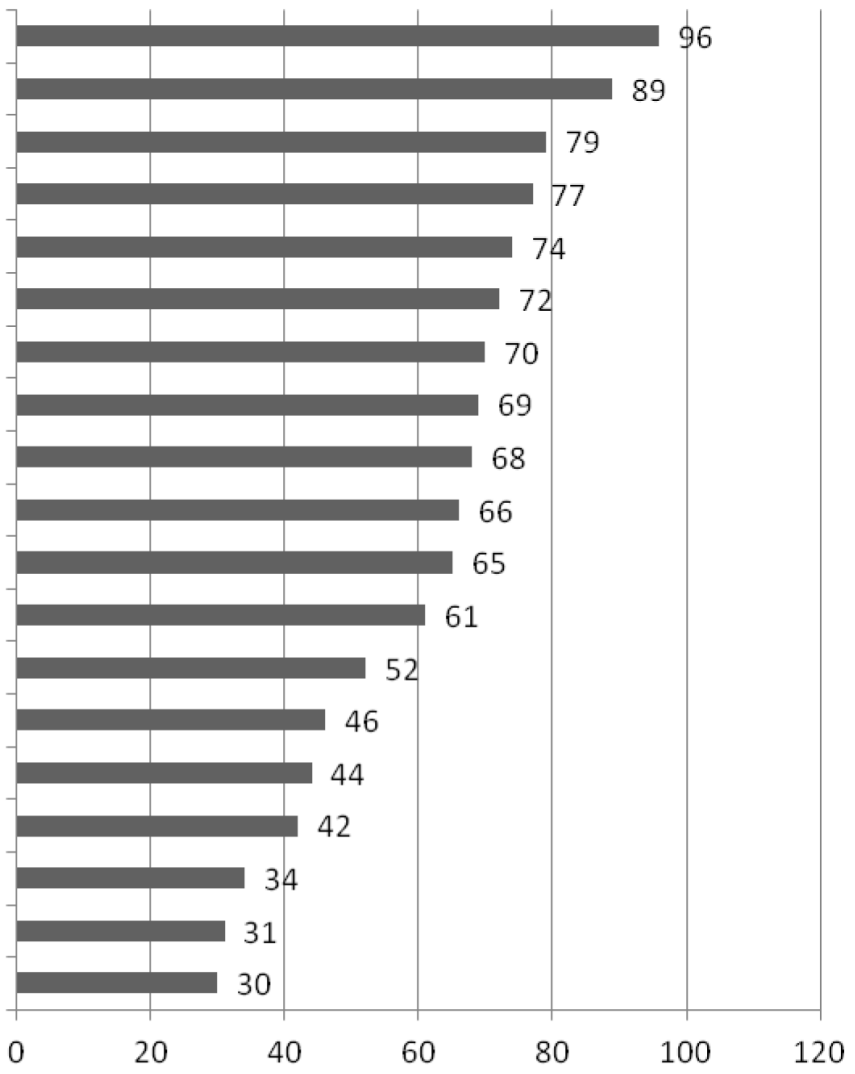

Figure 2. Different SBDs of the KDQOL.

\section{Discussion}

This is the first study which was conducted in Senegal where the quality of life of PD patients was assessed. The KDQoL was chosen because of its dialysis specific dimension [8] [9]. Some epidemiological and clinical variables had negative influences on our patients' QOL. Thus, age was correlated with alteration of QOL in the field of patient satisfaction. In a study involving patients with regular hemodialysis, there was a correlation in the areas of pain, quality of the environment, cognitive functions [10]. The weight was correlated with alteration of QOL in the fields of general health, physical activity, vitality and patient satisfaction. This is explained by the fact that significant water/salt overloads had a negative impact on cardiorespiratory performance. The low level 
of education was correlated with impaired QOL in the field of "limitations due to physical activity". This corroborates the results obtained by the same team on a hemodialysis population [10]. Social support was correlated with impaired QOL in the areas of physical activity, professional status and limitations due to mental activity. Similar results were found in hemodialysis [10]. This impairment of quality of life through social media can be explained by a feeling of guilt of patients, but especially by the fact that non-autonomous patients needed this support more.

About the SF-36, our results are consistent with the Figure 1 and Figure 2. We noted a slight similarity in the "General Health" and "Mental Health" areas. By contrast, it can be noted in our series that the "Limitations due to physical activity" and "Vitality" areas are altered in comparison with the studies of other authors (Figure 3). The results in the SF-36 in our study are far better than those obtained in hemodialysis [10] as shown in Figure 4 in connection with probably the best treatment and greater autonomy that the PD can offer.

Regarding KDQoL-SF average scores (SMD), the results of field limitations due to physical activity, quality of sexual activity, relationship and life and patient satisfaction showed a similarity with Boini in France [1] [2]. The results on the areas the sleep, friendly relations, physical activity, physical pain and burden of kidney disease corroborate those of Korea [11] (Figure 4). As for the average scores per dimension, it is noted that only the physical dimension is widely impaired. Indeed, our results in the mental health dimension were best compared to those of Turkey and Korea [11]-[13].

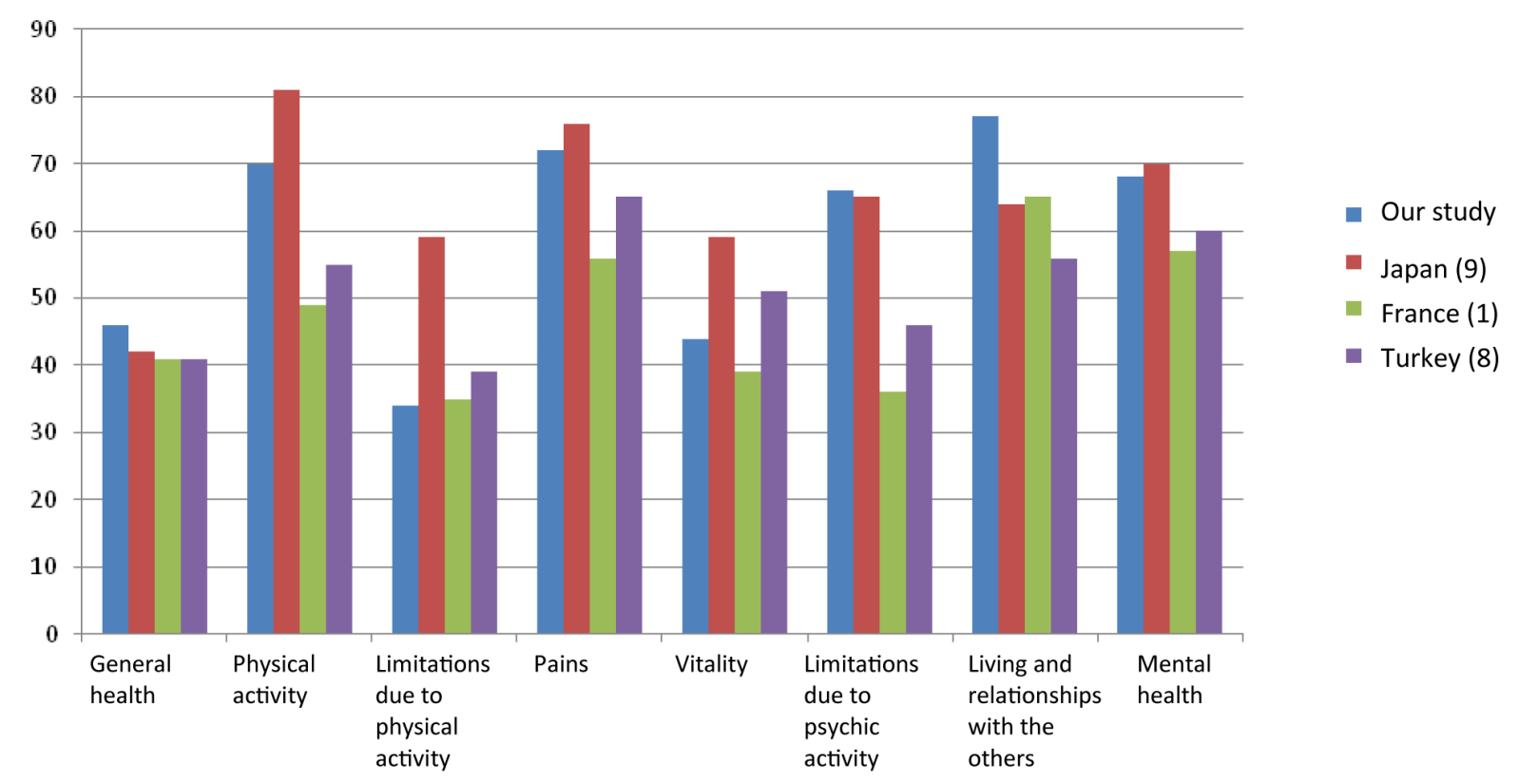

Figure 3. Histogram comparing quality of life as per SF-36.

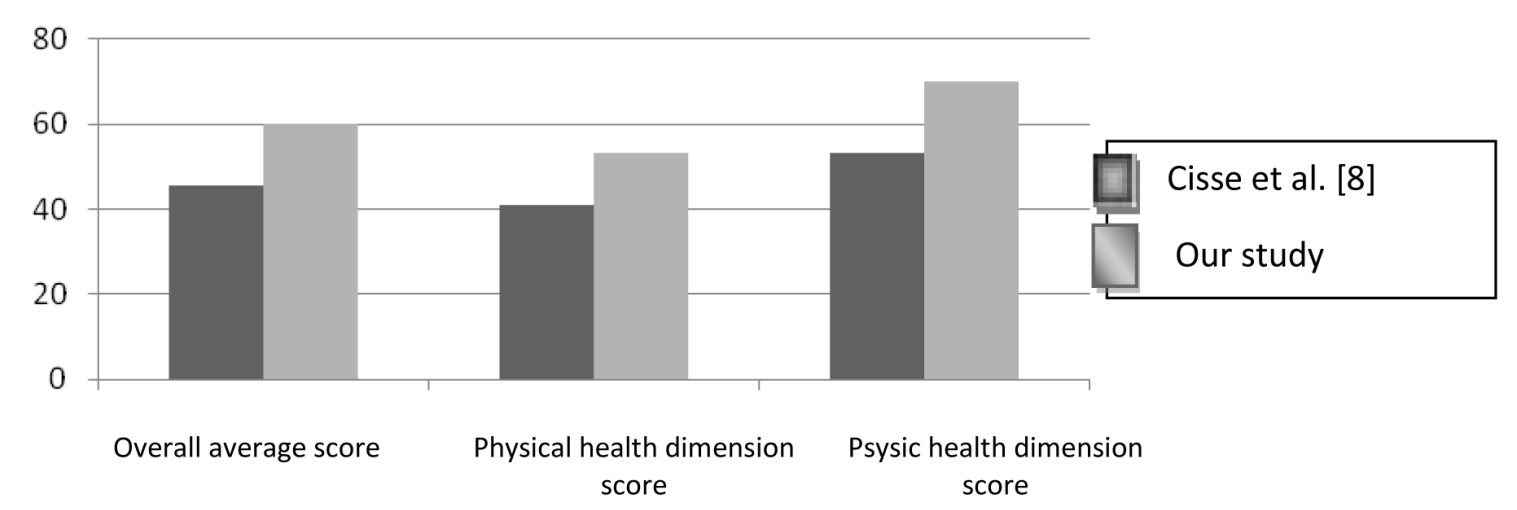

Figure 4. Histogram comparing SF-36 results. 


\section{Limitations of the Study}

The main limitation was in the translation and cross-cultural adaptation of the questionnaire. A simple translation in the national language (Wolof) is not enough and a very precise work is needed, particularly as far as exploring the concepts is concerned. You can either create new questionnaires or adapt Anglo-Saxon questionnaires. The size of the sample which is not very representative does not allow for a correct interpretation of the results.

\section{Conclusion}

The study shows a poor QOL in PD patients assessed with both SF-36 and KDQoL-SF tools. Physical health was the most impaired item. The main associated factors with QOL were age, weight, social and education level. Given the small sample, a study of a larger scale is necessary in order to better analyze the factors affecting the quality of life.

\section{References}

[1] Boini, S., Leplege, A., Loos Ayav, C., Francais, P., Ecosse, E. and Briancon, S. (2007) Mesure de la qualité de vie dans l'insuffisance rénale chronique terminale. Néphrologie \& Thérapeutique, 3, 372-383. http://dx.doi.org/10.1016/j.nephro.2007.05.005

[2] Boini, S., Bloch, J. and Briançon, S. (2009) Monitoring the Quality of Life of End-Stage Renal Disease Patients. Quality of life Report-REIN-Dialysis 2005. Néphrologie \& Thérapeutique, 5, S177-S237. http://dx.doi.org/10.1016/j.nephro.2007.05.005

[3] Seck, S.M., Doupa, D., Gueye, L. and Dia, C.A. (2014) Prevalence of Chronic Kidney Disease and Associated Factors in Senegalese Populations: A Community-Based Study in Saint-Louis. Nephro-Urology Monthly, 6, e19085. http://dx.doi.org/10.5812/numonthly.19085

[4] Cissé, M.M., Ka, E.F., Gueye, S., Seck, S.M., Tall, A., Niang, A. and Diouf, B. (2011) Dialyse péritonéale en milieu tropical, une réalité en Afrique. Médecine Tropicale, 71, 468-447.

[5] Ware Jr., J.E. and Sherbourne, C.D. (1992) The MOS 36-Item Short-Form Health Survey (SF-36). I. Conceptual Framework and Item Selection. Medical Care, 30, 473-483. http://dx.doi.org/10.1097/00005650-199206000-00002

[6] Kidney Disease Quality of Life Short Form (KDQOL-SFTM), Version 1.2 (2014). http://www.rand.org/content/dam/rand/www/external/health/surveys tools/kdqol/KDQOL12-Fren.PDF

[7] Charlson, M.E., Pompei, P., Ales, K.L. and MacKenzie, C.R. (1987) A New Method of Classifying Prognostic Comorbidity in Longitudinal Studies: Development and Validation. Journal of Chronic Diseases, 40, 373-383. http://dx.doi.org/10.1016/0021-9681(87)90171-8

[8] Hays, R.D., Kallich, J.D., Mapes, D.L., Coons, S.J. and Carter, W.B. (1994) Development of the Kidney Disease Quality of Life (KDQOL) Instrument. Quality of Life Research, 3, 329-338. http://dx.doi.org/10.1007/BF00451725

[9] Rettig, R.A., Sadler, J.H., Meyer, K.B., Wasson, J.H., Parkerson, G.R., Kants, B., et al. (1997) Assessing 1 Health and Quality of Life Outcomes in Dialysis: A Report of Institute of Medecine Workshop. American Journal of Kidney Diseases, 30, 140-155. http://dx.doi.org/10.1007/BF00451725

[10] Cisse, M.M., Ka, E.F., Gueye, S., Tall, A.O.L., Faye, M., Niang, A. and Diouf, B. (2012) Qualité de vie des patients en hémodialyse à Dakar (Sénégal): Quelles particularités pour les personnes vivant en milieu tropical? Medecine et sante tropicales, 22, 198-202.

[11] Yong, J.S., et al. (2007) Reliability and Validity of the Korean Version of Kidney Disease Quality of Life (KDQoL). Tohoku Journal of Experimental Medicine, 211, 321-329. http://dx.doi.org/10.1620/tjem.211.321

[12] Sayin, A., Mutluay, R. and Sindel, S. (2007) Quality of Life in Hemodialysis, Peritoneal Dialysis, and Transplantation Patient. Transplantation Proceedings, 39, 3047053. http://dx.doi.org/10.1016/j.transproceed.2007.09.030

[13] Yahiro, K., et al. (2003) Health-Related Quality of Life and Caregiver Burden among Peritoneal Dialysis Patients and Their Family Caregivers in Japan. Peritoneal Dialysis International, 23, S200-S205. 